\title{
Workshop Penulisan Artikel Ilmiah sebagai Pengembangan Keprofesian Berkelanjutan Guru di Sekolah Menengah Atas
}

\author{
Imam Kusmaryono*1, Mochamad Abdul Basir ${ }^{2}$ \\ 1,2, Prodi Pendidikan Matematika, Universitas Islam Sultan Agung, Semarang \\ *e-mail: kusmaryono@unissula.ac.id ${ }^{1}$, abdulbasir@unissula.ac.id² ${ }^{2}$
}

\begin{abstract}
This community service is carried out with the aim of improving the skills of writing scientific articles for teachers in the Kendal district, Central Java province. Strategy activities through workshops and assistance in writing scientific articles as a sustainable teacher professional development. The outputs of this workshop are (1) Teachers have good scientific article writing skills for teacher professional development, and (2) Teachers can produce scientific articles to be published in accredited national journals. The results of the workshop were effective in improving the skills of teachers in writing scientific articles where $70 \%$ of participants succeeded in compiling scientific articles.
\end{abstract}

Keywords: Workshop, Article Writing, Continuous Professional Development, Teacher.

\begin{abstract}
Abstrak
Pengabdian kepada masyarakat ini dilakukan dengan tujuan meningkatkan keterampilan menulis artikel ilmiah bagi para guru di wilayah kabupaten Kendal, proponsi Jawa Tengah. Strategi kegiatan melalui workshop dan pendampingan penulisan artikel ilmiah sebagai pengembangan profesi guru berkelanjutan. Luaran hasil kegiatan workshop ini adalah (1) Guru-guru memiliki keterampilan menulis artikel ilmiah yang baik sebagai pengembangan profesi guru, dan (2) Guru-guru dapat menghasilkan artikel ilmiah untuk dipublikasikan dalam jurnal nasional terkareditasi. Hasil kegiatan workshop efektif meningkatkan keterampilan guru menulis artikel ilmiah dimana $70 \%$ peserta berhasil menyusun artikel ilmiah
\end{abstract}

Kata kunci: workshop, menulis artikel, $P K B$, guru

\section{PENDAHULUAN}

Menulis adalah kemampuan untuk mengungkapkan gagasan dalam bentuk tulisan sehingga menjadi sebuah sumber informasi bagi masyarakat. Jika guru tidak mampu melakukannya, guru tidak dapat melakukan proses pendidikan dan pembelajaran dengan baik (Defazio et al., 2010). Untuk menghadapi kondisi yang sangat dinamis dalam kehidupan di masyarakat, mau tidak mau setiap guru harus mengembangkan keterampilan menulis dan tidak ada alasan bahwa seorang guru tidak dapat menulis. Kegiatan menulis sangat bermanfaat dan dapat dijadikan sebagai inspirasi bagi guru-guru yang lain untuk mencoba menulis karya ilmiah

Penulisan artikel dalam jurnal ilmiah memiliki banyak tantangan yang berbeda berdasarkan pada tujuan penulisan. Satu penggunaan umum penulisan artikel di jurnal oleh guru adalah untuk mempromosikan pemikiran dan refkleksi pembelajaran (Moses \& Mohamad, 2019). Permenpan No. 16 tahun 2009 pasal 16 ayat 2 menyebut bahwa untuk kenaikan jabatan/pangkat dari golongan ruang III/a sampai IV/e guru wajib melakukan Pengembangan Keprofesian Berkelanjutan (PKB) (Putri, 2020). Penjelasan lebih lanjut, bahwa salah satu kegiatan PKB bagi guru ialah publikasi ilmiah (Permenpan Nomor 16 Tahun 2009 Tentang Jabatan Fungsional Guru dan Angka Kreditnya, 2009). Oleh karena peraturan tersebut bersifat mengikat, maka setiap guru Indonesia wajib melaksanakan kegiatan PKB.

Analisis situasi awal terhadap guru-guru di wilayah kabupaten Kendal propinsi Jawa Tengah, berasarkan angket diperoleh data bahwa 70\% guru-guru di wilayah kabupaten Kendal tertunda kenaikan pangkatnya karena tidak terpenuhinya syarat memiliki artikel ilmiah. Hasil 
angket tentang faktor penghambat rendahnya minat menulis artikel adalah $80 \%$ karena kurangnya pelatihan menulis artikel ilmiah (menduduki peringkat tertinggi). Factor lain karena kurang percaya diri (15\%), dan kurangnya kosa kata dan tata bahasa yang baik untuk menulis artikel ilmiah (5\%) (Fareed et al., 2016; Misbah et al., 2017).

Menulis juga menjadi bagian dalam memperjuangkan syiar Islam dimana sejatinya kita sedang mengerjakan amal sholeh yang tiada putusnya. Jadi, secara formal pengembangan professional merupakan bagian dari kisaran pengalaman yang dapat menghasilkan pembelajaran profesional. Allah SWT berfirman: "Dan dia termasuk orang-orang yang beriman dan saling berpesan untuk bersabar dan saling berpesan untuk berkasih sayang." (QS. Al-Balad, 90: 17).

Pengembangan profesional yang efektif sebagai pembelajaran profesional terstruktur akan menghasilkan perubahan pada pengetahuan dan praktik guru, dan peningkatan dalam hasil pembelajaran (Putri, 2020). Ali bin Abi Thalib RA (Ash-Shalabi, 2015) pernah berkata "Ikatlah ilmu dengan menuliskannya". Pernyataan tersebut menegaskan bahwa ilmu tidak selayaknya hanya diketahui oleh diri sendiri, namun juga harus disebarkan kepada orang lain. Para ulama terdahulu menginfaqkan harta, waktu dan pikiran untuk mengikat ilmu agama dengan menghimpunnya menjadi buku dimana hal tersebut merupakan sedekah intelektual dan menjadi sesuatu yang patut diteladani.

Berdasarkan analisis situasi diperoleh permasalahan yang dialami mitra dan harus dicarikan solusinya adalah: Bagaimana bentuk pelatihan guru untuk meningkatkan keterampilan menulis artikel ilmiah? Adapun luaran yang diharapkan dari kegiatan pengabdian kepada masyarakat ini adalah (1) Guru-guru memiliki keterampilan menulis artikel ilmiah yang baik sebagai pengembangan profesi guru, dan (2) Guru-guru dapat menghasilkan artikel ilmiah untuk dipublikasikan dalam jurnal nasional ber-ISSN atau jurnal nasional terkareditasi.

Permasalahan yang terjadi pada para guru di wilayah kabupaten Kendal propinsi Jawa Tengah dipandang perlu dan mendesak harus ada solusi sebagai upaya untuk meningkatkan keterampilaan menulis artikel ilmiah para guru. Untuk memecahkan permasalahan ini disusun program pengabdian kepada masyarakat "Penugasan doktor dan dosen di sekolah sebagai strategi pengembangan professional yang efektif" yang digagas oleh Fakultas Keguruan dan Ilmu Pendidikan, Unisversitas Islam Sultan Agung (UNISSULA) Semarang. Kegiatan Pengabdian Masyarakat ini dikemas melalui strategi (metode) workshop. Tema workshop adalah "Workshop dan Pendampingan Penulisan Artikel Ilmiah Sebagai Pengembangan Profesi Guru Berkelanjutan dan Investasi keilmuan".

\section{METODE}

Kegiatan workshop dilaksanakan tanggal 1, 3, dan 10 Juli 2021. Kegiatan workshop bertempat di SMA dan SMK Negeri di kabupaten Kendal propinsi Jawa Tengah. Kegiatan workshop ini menggundang peserta sebanyak 102 guru yang berasal dari 3 sekolah yaitu SMA Negeri 1 Pegandon, SMK Negeri 3 Kendal, dan SMK Negeri 4 Kendal. Sebelum kegiatan pengabdian kepada masyarakat ini dilaksanakan, terlebih dahulu diawali dengan penandatangan MoU antara sekolah dengan FKIP Universitas Islam Sultan Agung.

Tim pengabdian kepada masyarakat ini terdiri dari 6 dosen Program Studi Pendidikan Matematika, FKIP Unissula yaitu: Dr. Imam Kusmaryono, M.Pd. (Ketua), M. Abdul Basir, M.Pd. (Sekretaris), dan anggota (1) Dr. Hevy Risqi Maharani, M.Pd., (2) Nila Ubaidah, M.Pd., (3) Dyana Wijayanti, M.Pd., Ph.D, dan (4) M. Aminudin, M.Pd. Adapun materi workshop disajikan pada Tabel 1 berikut. 
Tabel 1. Materi Workshop Penulisan Artikel Ilmiah

\begin{tabular}{cl}
\hline No. & \multicolumn{1}{c}{ Materi Workshop } \\
\hline M1 & Urgensi Menulis Artikel Ilmiah \\
& Dalam Pengembangan Profesi Guru Berkelanjutan \\
M2 & Mekanisme dan Sistematika Penulisan Artikel Ilmiah \\
M3 & Tips Menulis Artikel Ilmiah \\
M4 & $\begin{array}{l}\text { Pendampingan Penulisan Artikel Ilmiah (Kelompok dan } \\
\text { Individu) }\end{array}$ \\
\hline
\end{tabular}

Kegiatan pengabdian kepada masyarakat ini dikemas dalam bentuk workshop. Adapun pelaksanaan kegiatan pengabdian masyarakat dilakukan melalui 5 (lima) tahap sebagai berikut (lihat Gambar 1). Tahap (1): menyiapkan DOkumen MOA, dan Sosialisasi kegiatan yaitu melakukan pendekatan kepada Kepala Sekolah untuk berkonsultasi tentang ide kegiatan pengabdian kepada masyarakat. Kemudian kami mensosialisasikan kegiatan dengan menyebarkan angket kepada para guru untuk menjaring permasalahan. Pada tahap ini termasuk adalah persiapan kegiatan pengabdian masyarakat yaitu menentukan jadwal kegiatan, peserta kegiatan, serta materi dan nara sumber. Kegiatan pelatihan dikemas dalam bentuk workshop. Tahap (2) Pelaksanaan kegiatan Workshop diharapkan tepat waktu, tepat sasaran, materi dan nara sumber siap melaksanakan kegiatan. Tahap (3): Pendampingan, dimana peserta dibagi menjadi 6 kelompok. Setiap kelompok didampingi oleh 1 orang dosen pembimbing. Tahap (4): Evaluasi dilakuan untuk mengetahui sejauh mana keberhasilan kegiatan dan kendala-kendala yang dihadapi. Tahap (5) Membantu guru untuk mengirim artikel ke jurnal online. Strategi Pengembangan Workshop dan Pendampingan Penulisan Artikel Ilmiah dalam kegiatan pengabdian masyarakat ini ditampilkan pada gambar 1 berikut.

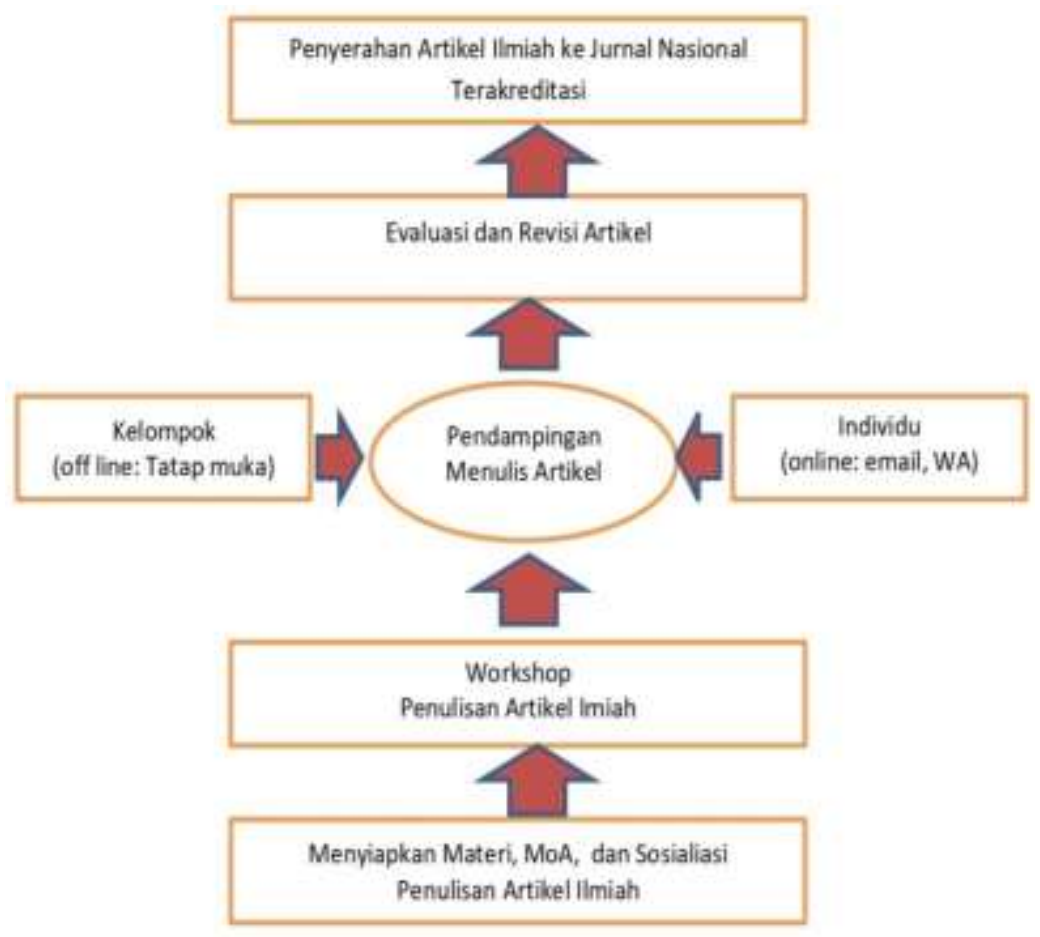

Gambar 1. Strategi Pengembangan Workshop

Diakhir kegiatan workshop, Tim pengabdian masyarakat memberikan angket evaluasi kegiatan kepada peserta. Angket ini bertujuan untuk memperoleh informasi tentang kepuasan peserta pelatihan dan mendapat masukan serta saran untuk kegiatan pengabdian masyarakat di waktu mendatang. 


\section{HASIL DAN PEMBAHASAN}

Pada hari pertama, workshop berjalan dengan lancar. Kegiatan wokshop dimulai pada pukul 08.00 - 13.00 WIB dengan protocol kesehatan yang ketat. Kegiatan ini dihadiri oleh para kepala Sekolah dan guru. Jumlah peserta yang hadir sebanyak 102 orang. Setelah pemaparan materi workshop oleh Tim dosen UNISSULA dilanjutkan dengan Tanya jawab dengan peserta. Peserta sangat antusias dengan banyak mengajukan pertanyaan seputar teknik dan tips menulis artikel ilmiah.

Para guru sebagian besar telah menyiapkan draft artikel untuk dikonsultasikan kepada Tim pengabdian dosen UNISSULA. Di sisi lain banyak guru merasa bahwa tugas menulis artikel jurnal mendorong eksplorasi dan mengambil risiko yang sangat berat (Gündoğmuş, 2018). Hal ini didasarkan pada hasil angket awal yang diberikan kepada para guru tentang hambatan menulis artikel ilmiah. Pelaksanaan kegiatan pada hari pertama didokumentasikan pada Gambar 2.

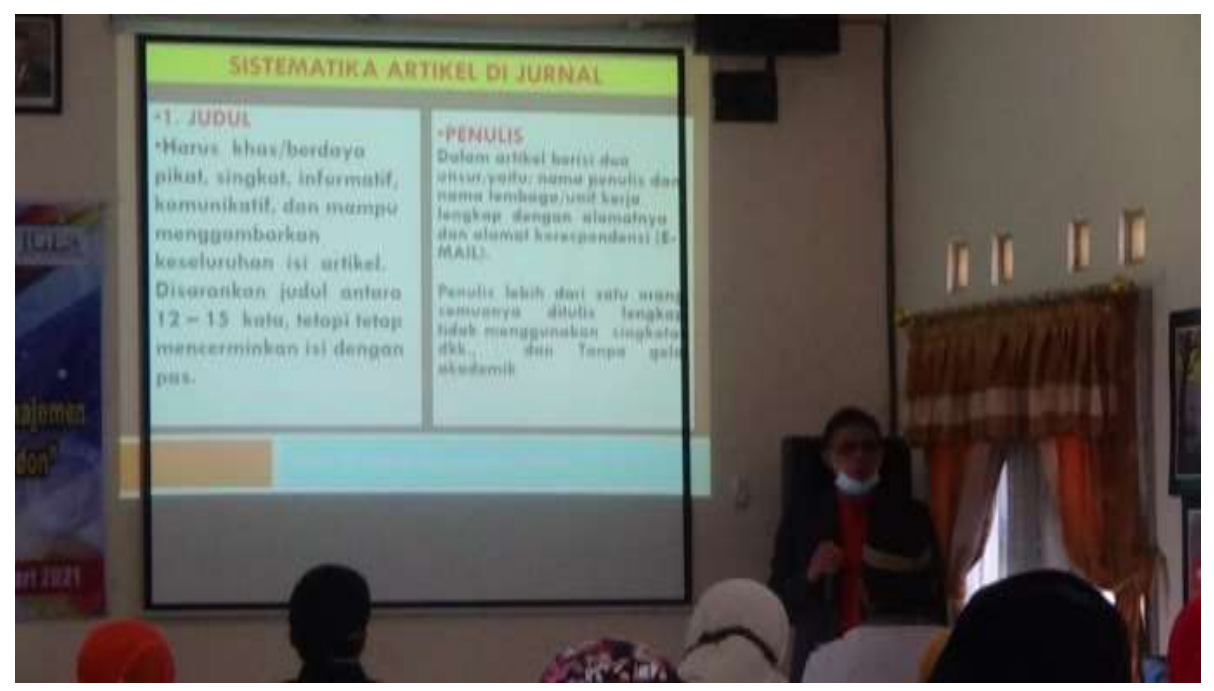

Gambar 2. Pelaksanaan Workshop Hari Pertama (1 Juli 2021)

Para guru sebagian besar telah menyiapkan draft artikel untuk dikonsultasikan kepada Tim pengabdian dosen UNISSULA. Di sisi lain banyak guru merasa bahwa tugas menulis artikel jurnal mendorong eksplorasi dan mengambil risiko yang sangat berat (Gündoğmuş, 2018). Hal ini didasarkan pada hasil angket awal yang diberikan kepada para guru tentang hambatan menulis artikel ilmiah.

Hari kedua kegiatan workshop diisi dengan praktik menyusun artikel ilmiah. Kegiatan dilakukan secara berkelompok sesuai bidang ilmu yang serumpun. Tim pengabdian dosen UNISSULA memberi masukan dan saran. Pada sesi ini Tim pengabdian dosen UNISSULA mencatat bahwa pada umumnya artikel yang disusun oleh guru masih kurang baik, terutama tentang penyusunan paragraf yang baik, kalimat yang efektif, kosa kata yang tepat, dan bahasa ilmiah yang digunakan dalam menyusun artikel (Gündoğmuş, 2018). Berdasarkan temuan ini, maka para guru diberikan tips cara menulis artikel yang baik untuk merevisi kekurangan (kelemahan) artikel tersebut. Namun dari hasil workshop pertemuan pertama ini berhasil diperoleh data tentang topik artikel yang dibuat oleh peserta. Artikel-artikel tersebut $77 \%$ berupa draft artikel yang potensial untuk dapat diterbitkan pada jurnal sesuai bidang ilmu. Berikut disajikan tabel draft artikel hasil workshop. 
Tabel 2. Topik-Topik Artikel Potensial Hasil Workshop

\begin{tabular}{rlc}
\hline No. & Topik - Subtopik & Frekuensi \\
\hline 1 & Penelitian Tindakan Kelas & 31 \\
2 & Laporan Pembelajaran & 18 \\
3 & Ide Konseptual & 11 \\
4 & Best Practice & 19 \\
\hline$*$ & Jumlah & 79 \\
\hline
\end{tabular}

Artikel yang ditulis oleh guru (Tabel 2) secara umum merefleksikan persepsi atau pemahaman mereka tentang situasi yang dihadapi dalam praktik mengajar mereka (Walker, 2006). Menulis artikel ilmiah yang efektif merupakan keterampilan yang melibatkan pembelajaran, pemahaman, aplikasi, dan sintesis pengetahuan baru (Defazio et al., 2010). Menulis dengan baik memerlukan lebih dari mengikuti konvensi menulis. Menulis juga meliputi inspirasi kreatif, pemecahan masalah, refleksi dan revisi yang menghasilkan naskah.

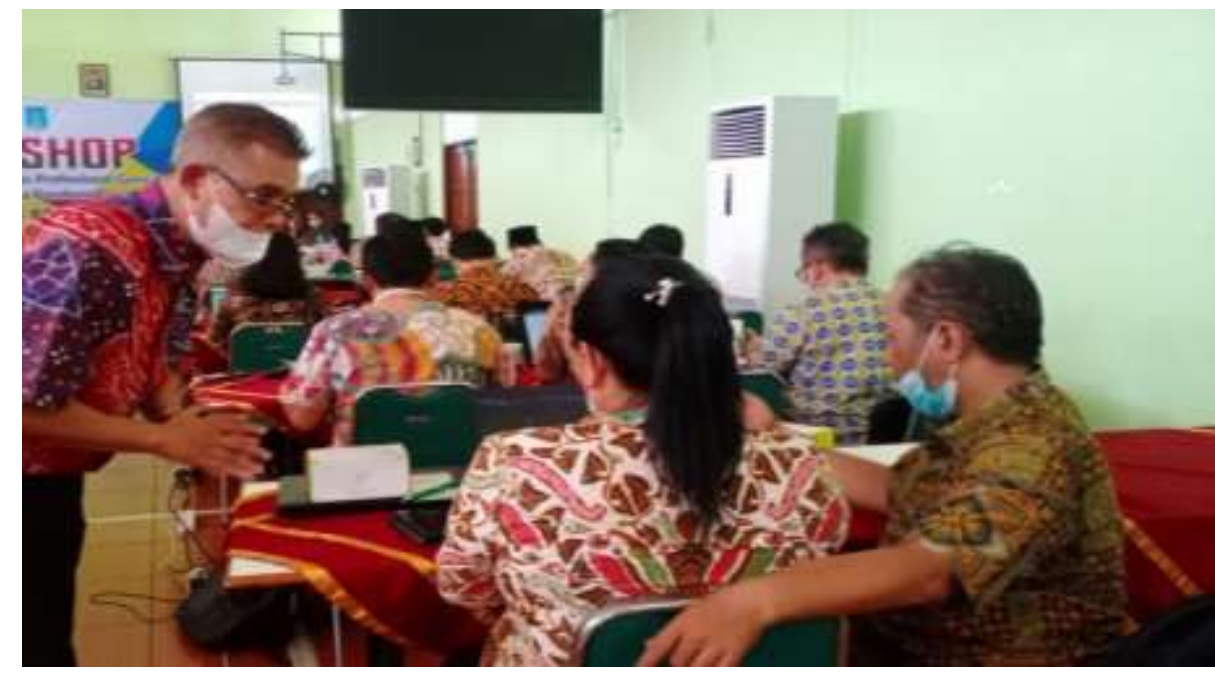

Gambar 3. Pendampingan Menulis Artikel Hari Kedua

Hari ketiga (3 Juli 2021) kegiatan workshop dilaksanakan secara online melalui aplikasi Google Zoom Meet (Koentjoro et al., 2021; Prabowo et al., 2021). Kegiatan lebih ditekankan pada konsultasi individu terkait artikel yang dibuat dan jurnal yang dituju untuk publikasi. Peserta mempelajari gaya selingkung dan template jurnal yang dituju sebagai media publikasi ilmiah. Setelah kegiatan hari ketiga selesai, pendampingan penulisan artikel masih terus dilakukan melalui e-mail dan WhatsApp grup. Para guru dapat berkonsultasi kapan saja sesuai topik artikel yang mereka tulis.

Seiring berjalannya waktu sampai sekarang ini, para peserta (guru) telah berkurang problem yang dihadapi setelah pelatihan (Afrin, 2016) dan berhasil mengirim (submit) artikelnya ke jurnal-jurnal online. Bahkan, beberapa guru yang mengikuti pelatihan, kini artikelnya ada yang sudah diterbitkan di jurnal online. Tim pengabdian merasa cukup puas dan bangga bahwa program pengabdian masyarakat yang dijalankan memberikan hasil yang positif bagi guru-guru di kabupaten Kendal, propinsi Jawa Tengah.

Di akhir kegiatan di hari ketiga, peserta workshop diminta untuk mengisi angket (kuesioner) tentang evaluasi kegiatan pengabdian masyarakat. Kuesioner dikirimkan dalam bentuk Google Form melalui grup WhatsApp. Hasil kuesioner yang telah diisi oleh peserta dianalisis secara kualitatif deskriptif. Hasil evaluasi kegiatan pengabdian, secara umum peserta menyambut baik dan menyatakan kegiatan sangat bermanfaar dalam pengembangan profesi guru berkelanjutan. Peserta juga mengungkapkan bahwa nara sumber sangat komunikatif, menguasai materi dan jelas dalam menyampaikan materi workshop. Sedangkan saran yang 
diberikan peserta adalah agar waktu pelatihan lebih lama dan tetap melayani konsultasi artikel meski kegiatan sudah selesai.

Tanggapan peserta terhadap pertanyaan terbuka (angket) menyatakan bahwa menulis itu penting. Kreatif menulis dapat membawa banyak keuntungan (Klimova, 2012) yaitu membantu kita untuk: (a) mengekspresikan kepribadian seseorang; (b) membina komunikasi; (c) mengembangkan keterampilan berpikir; (d) membuat argumen yang logis dan persuasif; (e) merefleksikan ide-ide dan mengevaluasi kembali; (f) memberikan dan menerima umpan balik; dan (g) investasi dalam mempersiapkan kesuksesan di sekolah dan pekerjaan. Apa pun alasannya, guru perlu memiliki keterampilan yang diperlukan untuk berkomunikasi secara efektif dalam format tertulis yang memungkinkan mereka untuk menjadi sukses menulis artikel ilmiah.

\section{SIMPULAN}

Workshop dan pendampingan penulisan artikel ilmiah sebagai pengembangan profesi guru berkelanjutan efektif meningkatkan keterampilan menulis artikel ilmiah para guru SMA Negeri 1 Pegandon, kabupaten Kendal, propinsi Jawa Tengah. Sebanyak 70\% dari 102 peserta (71 orang guru) berhasil menyusun artikel ilmiah untuk dipublikasikan di jurnal nasional. Apa pun alasannya, guru perlu memiliki keterampilan menulis yang diperlukan untuk berkomunikasi secara efektif dalam format tertulis yang memungkinkan mereka untuk menjadi sukses menulis artikel ilmiah.

Penulis tak lupa mengucapkan terima kasih atas partisipasi bapak ibu guru dan Kepala sekolah dari SMA Negeri 1 Pegandon, SMK Negeri 4 Kendal, dan SMK Negeri 3 Kendal di wilayah kabupaten Kendal, propinsi jawa Tengah yang telah berpartisipasi dan mendukung kegiatan pengabdian kepada masyarakat.

\section{DAFTAR PUSTAKA}

Afrin, S. (2016). Writing Problems of Non-English Major Undergraduate Students in Bangladesh: An Observation. Open Journal of Social Sciences, 4, 104-115. https://doi.org/10.4236/jss.2016.43016

Ash-Shalabi, P. D. A. M. (2015). Biografi Ali Bin Abi Thalib.

Defazio, J., Jones, J., Tennant, F., \& Hook, S. A. (2010). Academic literacy: The importance and impact of writing across the curriculum-A case study. Journal of the Scholarship of Teaching and Learning, 10(2), 34-47.

Fareed, M., Ashraf, A., \& Bilal, M. (2016). ESL Learners' Writing Skills: Problems, Factors and Suggestions. Journal of Education and Social Sciences, 4, 81-92. https://doi.org/10.20547/jess0421604201

Gündoğmuş, H. D. (2018). The Difficulties Experienced by Teachers in the Process of Primary Reading and Writing Instruction and Their Solution Offers for Eliminating These Difficulties. Universal Journal of Educational Research, 6, 333-339. https://doi.org/10.13189/ujer.2018.060216

Klimova, B. F. (2012). The importance of writing. Paripex - Indian Journal of Research, 2(1), 9-11. https://doi.org/10.15373/22501991/jan2013/4

Koentjoro, M. P., Dewantara, B., Putra, P., \& Donastin, A. (2021). Workshop Online : Prosedur Analisis Multidrug-Resistance Tuberculosis ( MDR-TB ) dengan Teknik Sekuensing Bagi 
Guru SD , SMP dan SMA. Caradde: Jurnal Pengabdian Kepada Masyarakat, 3(3), 513-520.

Misbah, N. H., Mohamad, M., Yunus, M., \& Ya'acob, A. (2017). Identifying the Factors Contributing to Students' Difficulties in the English Language Learning. Creative Education, 8, 19992008. https://doi.org/10.4236/ce.2017.813136

Moses, R. N., \& Mohamad, M. (2019). Challenges faced by students and teachers on writing skills in ESL contexts: A literature review. Creative Education, 10(13), 3385-3391. https://doi.org/10.4236/ce.2019.1013260

Permenpan Nomor 16 tahun 2009 tentang Jabatan Fungsional Guru dan Angka Kreditnya, Kementrian Negara Pendayagunaan Aparatur Negara Dan Reformasi Birokrasi 1 (2009).

Prabowo, A., Suyatno, S. B., \& Ikawati, J. (2021). Pelatihan dan Pendampingan Pengembangan Subject Specific Pedagogy ( SSP ) Matematika Berbasis Learning Management System ( LMS ) Sebagai Sarana Pembelajaran Matematika. Caradde: Jurnal Pengabdian Kepada Masyarakat, 3(3), 497-506.

Putri, R. E. (2020). A preliminary study: The urgency of Scientific paper of science teacher. Pelita Eksakta, 3(1), 21. https://doi.org/10.24036/pelitaeksakta/vol3-iss1/86

Walker, S. E. (2006). Journal writing as a teaching technique to promote reflection. Journal of Athletic Training, 41(2), 216-221. 